\title{
Assessment of independent predictors for long-term mortality between women and men after coronary artery bypass grafting: Are women different from men?
}

Ioannis K. Toumpoulis, MD, ${ }^{\mathrm{a}, \mathrm{b}}$ Constantine E. Anagnostopoulos, MD, ${ }^{\mathrm{a}, \mathrm{b}}$ Sandhya K. Balaram, MD, ${ }^{\mathrm{a}}$ Chris K. Rokkas, MD, Daniel G. Swistel, MD, ${ }^{\text {a }}$ Robert C. Ashton, Jr, MD, and Joseph J. DeRose, Jr, MDa

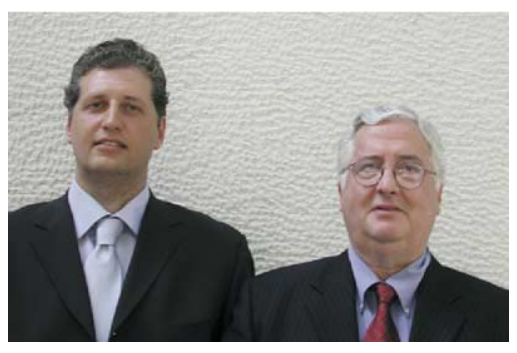

Drs Toumpoulis (left) and Anagnostopoulos (right)

See related editorial on page 264 .
Objective: The long-term mortality of coronary artery bypass grafting in women in not certain. The purpose of this study was to determine and compare risk factors for long-term mortality in women and men undergoing coronary artery bypass grafting.

Methods: Between 1992 and 2002, 3760 consecutive patients (2598 men and 1162 women) underwent isolated coronary artery bypass grafting. Long-term survival data were obtained from the National Death Index (mean follow-up, $5.1 \pm 3.2$ years). Multivariable Cox regression analysis was performed, including 64 preoperative, intraoperative, and postoperative factors separately in women and men.

Results: There were no differences in in-hospital mortality (2.7\% in men vs $2.9 \%$ in women, $P=.639)$ and 5 -year survival $(82.0 \% \pm 0.8 \%$ in men vs $81.1 \% \pm 1.3 \%$ in women, $P=.293$ ). After adjustment for all independent predictors of long-term mortality, female sex was an independent predictor of improved 5-year survival (hazard ratio, $0.82 ; 95 \%$ confidence interval, $0.71-0.96 ; P=.014$ ). Twenty-one independent predictors for long-term mortality were determined in men, whereas only 12 were determined in women. There were 9 common risk factors (age, ejection fraction, diabetes mellitus, $\geq 2$ arterial grafts, postoperative myocardial infarction, deep sternal wound infection, sepsis and/or endocarditis, gastrointestinal complications, and respiratory failure); however, their weights were different between women and men. Malignant ventricular arrhythmias, calcified aorta, and preoperative renal failure were independent predictors only in women. Emergency operation, previous cardiac operation, peripheral vascular disease, left ventricular hypertrophy, current and past congestive heart failure, chronic obstructive pulmonary disease, body mass index of greater than 29 , preoperative dialysis, thrombolysis within 7 days before coronary artery bypass grafting, intraoperative stroke, and postoperative renal failure were independent predictors only in men.

Conclusions: Despite equality between sexes in early outcome and superiority of female sex in long-term survival, there were 3 independent predictors for long-term mortality after coronary artery bypass grafting unique for women compared with 12 for men. Clinical decision making and follow-up should not be influenced by stereotypes but by specific findings.

$\mathrm{T}$ he outcome of coronary artery bypass grafting $(\mathrm{CABG})$ in men and women has been the object of intense debate in numerous studies. A higher early mortality (in-hospital or 30-day mortality) in women than in men after CABG has been observed by several researchers. ${ }^{1-6}$ In addition, female sex is involved as a risk factor both in Society for Thoracic Surgeons risk modeling, ${ }^{7}$ which is the largest cardiac surgery database in the world, and in the EuroSCORE algorithm, ${ }^{8}$ which is one of the best-established and validated models for contemporary practice in cardiac surgery. However, female sex might simply be a marker 


$$
\begin{aligned}
& \text { Abbreviations and Acronyms } \\
& \begin{aligned}
\mathrm{CABG} & =\text { coronary artery bypass grafting } \\
\mathrm{CI} & =\text { confidence interval } \\
\mathrm{HR} & =\text { hazard ratio } \\
\mathrm{OR} & =\text { odds ratio }
\end{aligned}
\end{aligned}
$$

of a high-risk profile, ${ }^{9}$ and thus after adjustment for confounding factors, it is not an independent predictor of early mortality. ${ }^{10-16}$

There is also less known regarding long-term survival after CABG in women, and differences between female and male sex have been studied less extensively. Most recent studies with long-term outcome provide evidence that between 5 and 7 years after CABG surgery, the results are the same for women compared with those for men, ${ }^{1,4,12,13,15,17}$ whereas few studies have shown a better long-term survival for women compared with men. ${ }^{10,18,19}$

The primary purpose of the present study was to determine and compare independent predictors for long-term mortality in women and men undergoing CABG. We also evaluated mortality between women and men both early and late after CABG surgery.

\section{Patients and Methods \\ Patient Population and Data}

Our study consisted of 3760 consecutive patients (2598 men and 1162 women) who underwent isolated CABG between January 1992 and March 2002 at the St Luke's-Roosevelt Hospital Center, a University Hospital of Columbia University. Data were prospectively collected during admission as part of routine clinical practice and entered into the New York State adult cardiac surgery report for the variables shown in Table 1. The definitions of the used variables were derived from the New York State adult cardiac surgery report, and we have mentioned some of them in our previous publications. ${ }^{20-23}$ Risk stratification was performed according to EuroSCORE. ${ }^{8}$

\section{Data Analysis}

Long-term patient mortality data were obtained from the United States Social Security Death Index database (http:// ssdi.genealogy.rootsweb.com). The sensitivity of the National Death Index to identify deaths is between $92 \%$ and $99 \%$, depending on which identifiers are available. ${ }^{24}$ Social Security number alone has the best accuracy of any combination of other identifiers (eg, first initial, last name, day of birth, month of birth, and year of birth), with a sensitivity of $97 \%$ and a specificity of $99 \% .{ }^{24}$ In this study we used only Social Security numbers, which were available in most patients (99.1\%), and this allowed avoiding use of patients' names. In addition, patients without a Social Security num- ber $(n=34)$ were censored at the time of discharge from the hospital. The Death Index was queried in September 2002, and patients not found there were assumed to be alive at that date.

\section{Statistical Methods}

Numeric variables were presented as the mean \pm standard deviation and were compared with the independent Student $t$ test or the Mann-Whitney $U$ test where appropriate. Discrete variables were summarized by percentages and were compared with the Fisher exact test or the $\chi^{2}$ test where appropriate. Kaplan-Meier survival curves were constructed for women and men and were compared with the log-rank test. $^{25}$

The effect of female sex on 30-day mortality after CABG was determined by using logistic regression analysis. ${ }^{26}$ All 64 preoperative, intraoperative, and postoperative variables were entered into the model. Variables were evaluated first univariately and then multivariately. The model selection was done with the backward stepwise method starting from all variables with a $P$ value of less than .05 in univariate analyses. Female sex was forced to remain in the multivariate model, and odds ratios (ORs) and 95\% confidence intervals (CIs) were calculated.

The effect of female sex on long-term mortality after CABG was determined by using Cox regression analysis. ${ }^{27}$ In the whole database all 64 preoperative, intraoperative, and postoperative variables were entered into the model. Variables were evaluated first univariately and then multivariately. The model selection was done with backward stepwise method starting from all variables with a $P$ value of less than .05 in univariate analyses. The model was then confirmed by using forward stepwise selection. Female sex was forced to remain in the multivariate model, and hazard ratios (HR) and CIs were calculated.

Independent predictors for long-term mortality after CABG were determined in men and women by using Cox regression analysis according to the procedure described above separately in the subgroup of men $(n=2598)$ and that of women $(n=1162)$. All analyses were performed with SPSS 11.0 software (SPSS, Inc, Chicago, Ill), and all $P$ values are 2 tailed.

\section{Results}

\section{Clinical Characteristics, Early Outcome, and Long- term Survival}

A total of 3760 patients were operated on during the study period, including $1162(30.9 \%)$ female patients and 2598 (69.1\%) male patients. During 19,335 person-years of follow-up (mean follow-up, $5.1 \pm 3.2$ years), 764 (20.3\%) deaths were recorded. Patient and disease preoperative, intraoperative, and postoperative characteristics are summarized in Table 1. Women had higher EuroSCOREs, were 
TABLE 1. Patient and disease preoperative, intraoperative, and postoperative characteristics in men and women undergoing CABG

\begin{tabular}{|c|c|c|c|}
\hline Variable & $\begin{array}{l}\text { CABG in men } \\
(\mathrm{n}=2598)\end{array}$ & $\begin{array}{c}\text { CABG in women } \\
(\mathrm{n}=1162)\end{array}$ & $P$ value \\
\hline \multicolumn{4}{|l|}{ Preoperative characteristics } \\
\hline EuroSCORE & $5.90 \pm 3.51$ & $7.31 \pm 3.39$ & $<.001$ \\
\hline Age $(y)$, mean $\pm S D$ & $63.2 \pm 10.2$ & $66.2 \pm 10.4$ & $<.001$ \\
\hline \multicolumn{4}{|l|}{ Race } \\
\hline White, $\mathrm{n}(\%)$ & $1816(69.9)$ & $644(55.4)$ & $<.001$ \\
\hline Black, n (\%) & $363(14.0)$ & $287(24.7)$ & $<.001$ \\
\hline Other, n (\%) & $419(16.1)$ & $231(19.9)$ & .005 \\
\hline \multicolumn{4}{|l|}{ Vessels involved } \\
\hline Single-vessel disease, n (\%) & $120(4.6)$ & $85(7.3)$ & .001 \\
\hline Two-vessel disease, $\mathrm{n}(\%)$ & $564(21.7)$ & $272(23.4)$ & .247 \\
\hline Three-vessel disease, $n(\%)$ & $1914(73.7)$ & $805(69.3)$ & .005 \\
\hline Unstable angina, n (\%) & $1728(66.5)$ & $842(72.5)$ & $<.001$ \\
\hline Previous MI (most recent), n (\%) & $1316(50.7)$ & $536(46.1)$ & .010 \\
\hline Transmural Ml, n (\%) & $950(36.6)$ & $328(28.2)$ & $<.001$ \\
\hline More previous MI, n (\%) & $474(18.2)$ & $187(16.1)$ & .109 \\
\hline Previous cardiac operation, $\mathrm{n}(\%)$ & $203(7.8)$ & $62(5.3)$ & .006 \\
\hline $\mathrm{CCS}$ angina class, mean $\pm \mathrm{SD}$ & $3.6 \pm 0.7$ & $3.7 \pm 0.5$ & $<.001$ \\
\hline \multicolumn{4}{|l|}{ Urgency of operation } \\
\hline Emergency, n (\%) & $193(7.4)$ & $105(9.1)$ & .092 \\
\hline Urgent, n (\%) & $1561(60.1)$ & $765(65.8)$ & .001 \\
\hline Elective, n (\%) & $844(32.5)$ & $292(25.1)$ & $<.001$ \\
\hline Hemodynamic instability, n (\%) & $62(2.4)$ & $27(2.3)$ & .907 \\
\hline Shock, n (\%) & $10(0.4)$ & $5(0.4)$ & .786 \\
\hline \multicolumn{4}{|l|}{ Ejection fraction categories } \\
\hline$>50 \%, \mathrm{n}(\%)$ & $700(27.0)$ & $352(30.3)$ & .035 \\
\hline $30 \%-50 \%, n(\%)$ & $1471(56.6)$ & $658(56.6)$ & .997 \\
\hline$<30 \%, \mathrm{n}(\%)$ & $427(16.4)$ & $152(13.1)$ & .008 \\
\hline Current CHF, n (\%) & $360(13.9)$ & $216(18.6)$ & $<.001$ \\
\hline Past CHF, n (\%) & $255(9.8)$ & $143(12.3)$ & .022 \\
\hline PVD, n (\%) & $458(17.6)$ & $265(22.8)$ & $<.001$ \\
\hline $\mathrm{BSA}$, mean $\pm S D$ & $1.97 \pm 0.20$ & $1.75 \pm 0.19$ & $<.001$ \\
\hline \multicolumn{4}{|l|}{ BMI categories } \\
\hline$<24, \mathrm{n}(\%)$ & $2351(90.5)$ & $763(65.7)$ & $<.001$ \\
\hline $24-29, \mathrm{n}(\%)$ & $213(8.2)$ & $305(26.2)$ & $<.001$ \\
\hline$>29, \mathrm{n}(\%)$ & $34(1.3)$ & $94(8.1)$ & $<.001$ \\
\hline Hypertension, n (\%) & $1712(65.9)$ & $923(79.4)$ & $<.001$ \\
\hline COPD, n (\%) & $389(15.0)$ & $161(13.9)$ & .370 \\
\hline Diabetes mellitus, $\mathrm{n}(\%)$ & 748 (28.8) & $529(45.5)$ & $<.001$ \\
\hline Calcified aorta, $\mathrm{n}(\%)$ & $208(8.0)$ & $115(9.9)$ & .056 \\
\hline Renal failure, $\mathrm{n}(\%)$ & $56(2.2)$ & $26(2.2)$ & .874 \\
\hline Preoperative dialysis, $\mathrm{n}(\%)$ & $28(1.1)$ & $18(1.5)$ & .261 \\
\hline Hepatic failure, $\mathrm{n}(\%)$ & $3(0.1)$ & $3(0.3)$ & .381 \\
\hline
\end{tabular}

more likely to be of black race with lower body surface area, were older with higher rates of unstable angina, underwent emergency or urgent operations, had current or past congestive heart failure, had peripheral vascular disease, had a body mass index of greater than 29 , had hypertension, had diabetes mellitus, received intravenous nitroglycerine, and had left ventricular hypertrophy. Men had higher percent- ages of 3-vessel disease, had previous or transmural myocardial infarctions, had ejection fractions of less than $30 \%$, underwent preoperative thrombolysis, were smokers, received more arterial grafts, and received more distal anastomoses. There were no differences in early mortality and major postoperative complications; however, women had prolonged in-hospital length of stay. 
TABLE 1. Continued

\begin{tabular}{|c|c|c|c|}
\hline Variable & $\begin{array}{c}\text { CABG in men } \\
(n=2598)\end{array}$ & $\begin{array}{c}\text { CABG in women } \\
(\mathrm{n}=1162)\end{array}$ & $P$ value \\
\hline Immune deficiency, $\mathrm{n}(\%)$ & $26(1.0)$ & $10(0.9)$ & .856 \\
\hline Preoperative IABP, n (\%) & $143(5.5)$ & $66(5.7)$ & .828 \\
\hline Intravenous NTG, n (\%) & $415(16.0)$ & $235(20.2)$ & .001 \\
\hline LV hypertrophy, n (\%) & $636(24.5)$ & $333(28.7)$ & .007 \\
\hline Malignant ventricular arrhythmia, $\mathrm{n}(\%)$ & $69(2.7)$ & $27(2.3)$ & .551 \\
\hline Thrombolysis before surgical intervention, $\mathrm{n}(\%)$ & $152(5.9)$ & $44(3.8)$ & .009 \\
\hline Myocardial rupture, $\mathrm{n}(\%)$ & $4(0.2)$ & $1(0.1)$ & .999 \\
\hline Stent thrombosis, n (\%) & $12(0.5)$ & $4(0.3)$ & .789 \\
\hline Transfer to $\mathrm{OR}$ after catheterization, $\mathrm{n}(\%)$ & $28(1.1)$ & $16(1.4)$ & .417 \\
\hline Transfer to $\mathrm{OR}$ after $\mathrm{PCI}, \mathrm{n}(\%)$ & $14(0.5)$ & $8(0.7)$ & .644 \\
\hline Previous $\mathrm{PCl}$, this admission, $\mathrm{n}(\%)$ & $41(1.6)$ & $36(3.1)$ & .002 \\
\hline Previous $\mathrm{PCl}$, before this admission, $\mathrm{n}(\%)$ & $284(10.9)$ & $149(12.8)$ & .093 \\
\hline Smoking past 2 wk, n(\%) & $407(15.7)$ & $159(13.7)$ & .116 \\
\hline Smoking in previous year, $\mathrm{n}(\%)$ & $419(16.1)$ & $150(12.9)$ & .011 \\
\hline \multicolumn{4}{|l|}{ Intraoperative characteristics } \\
\hline Total bypass time $(\min )$, mean $\pm S D$ & $112 \pm 52$ & $108 \pm 51$ & .117 \\
\hline OPCAB, n (\%) & $163(6.3)$ & $83(7.1)$ & .319 \\
\hline Microscope use, n (\%) & $1097(42.2)$ & $434(37.3)$ & .005 \\
\hline$\geq 2$ Arterial grafts, $\mathrm{n}(\%)$ & $1557(59.9)$ & $524(45.1)$ & $<.001$ \\
\hline Anastomoses, mean $\pm \mathrm{SD}$ & $3.4 \pm 1.0$ & $3.2 \pm 1.0$ & $<.001$ \\
\hline \multicolumn{4}{|l|}{ Postoperative characteristics } \\
\hline 30-d mortality, $\mathrm{n}(\%)$ & $95(3.7)$ & $45(3.9)$ & .747 \\
\hline In-hospital mortality, n (\%) & $69(2.7)$ & $34(2.9)$ & .639 \\
\hline Length of stay $(d)$, mean $\pm S D$ & $10.6 \pm 11.6$ & $11.8 \pm 13.7$ & $<.001$ \\
\hline \multicolumn{4}{|l|}{ Postoperative complications } \\
\hline Intraoperative stroke, $\mathrm{n}(\%)$ & $61(2.3)$ & $37(3.2)$ & .137 \\
\hline Stroke $>24$ h, n (\%) & $13(0.5)$ & $12(1.0)$ & .081 \\
\hline Postoperative MI, n (\%) & $15(0.6)$ & $8(0.7)$ & .657 \\
\hline Bleeding-reoperation, $\mathrm{n}(\%)$ & $48(1.8)$ & $18(1.5)$ & .592 \\
\hline Deep sternal wound infection, $\mathrm{n}(\%)$ & $25(1.0)$ & $15(1.3)$ & .391 \\
\hline Gastrointestinal complications, n (\%) & $38(1.5)$ & $12(1.0)$ & .356 \\
\hline Renal failure-dialysis, $\mathrm{n}(\%)$ & $16(0.6)$ & $9(0.8)$ & .664 \\
\hline Sepsis-endocarditis, n (\%) & $24(0.9)$ & $12(1.0)$ & .721 \\
\hline Respiratory failure, $\mathrm{n}(\%)$ & $104(4.0)$ & $58(5.0)$ & .168 \\
\hline
\end{tabular}

$\overline{C A B G}$, Coronary artery bypass grafting; SD, standard deviation; $M I$, myocardial infarction; CCS, Canadian Cardiovascular Society; CHF, congestive heart failure; $P V D$, peripheral vascular disease; $B S A$, body surface area; $B M I$, body mass index; $C O P D$, chronic obstructive pulmonary disease; $I A B P$, intra-aortic balloon pump; $N T G$, nitroglycerine; $L V$, left ventricular; $O R$, operating room; $P C l$, percutaneous coronary intervention; $O P C A B$, off-pump coronary artery bypass.

Multivariate logistic regression analysis determined the independent predictors for 30-day mortality after CABG in the entire database (Table 2). Female sex was not an independent predictor for 30-day mortality (OR, $0.85 ; 95 \% \mathrm{CI}$, $0.55-1.31 ; P=.458$ ).

Freedom from all-cause mortality in men undergoing CABG at 5 and 10 years after CABG was $82.0 \% \pm 0.8 \%$ and $66.9 \% \pm 1.5 \%$, respectively, compared with $81.1 \% \pm$ $1.3 \%$ and $64.2 \% \pm 2.8 \%$ in women $(P=.293$, Figure 1$)$.

Independent Predictors for Long-term Mortality and Risk-adjusted Kaplan-Meier Curves

Twenty-one independent predictors for long-term mortality after $\mathrm{CABG}$ were determined in men, whereas only 12 were determined in women (Table 3). The difference in the number of patients between the female and male subgroups might account for the difference in the total number of independent predictors determined in each subgroup. We calculated the predictive score for long-term mortality for men and women on the basis of their independent predictors. The HR of the predictive score in men was 2.73 (95\% $\mathrm{CI}, 2.53-2.96 ; P<.001, \beta$ coefficient $=1.006$ ), and the HR of the predictive score in women was 2.72 (95\% CI, 2.413.07; $P<.001, \beta$ coefficient $=1.001$ ), indicating an excellent goodness of fit in both groups. There were 9 common independent predictors; however, their weights were different (Table 3). The crude HR for long-term mor- 
TABLE 2. Independent predictors for 30-day mortality after CABG

\begin{tabular}{lccc}
\hline Variable & Odds ratio & 95\% Confidence interval & P value \\
\hline Age (continuous variable) & 1.051 & $1.029-1.074$ & $<.001$ \\
Emergency operation & 2.75 & $1.63-4.65$ & $<.001$ \\
Shock & 4.67 & $1.21-17.99$ & .025 \\
Preoperative renal failure & 1.47 & $1.22-1.78$ & .025 \\
Total bypass time (continuous variable) & 1.005 & $1.001-1.009$ & .014 \\
Intraoperative stroke & 2.53 & $1.16-5.51$ & .020 \\
Postoperative myocardial infarction & 10.29 & $3.43-30.93$ & $<.001$ \\
Gastrointestinal complications & 5.61 & $2.55-12.37$ & $<.001$ \\
Respiratory failure & 4.35 & $2.56-7.38$ & $<.001$ \\
Female sex & 0.85 & $0.55-1.31$ & .458 \\
\hline
\end{tabular}

tality after CABG in women was 1.08 (95\% CI, 0.93-1.26; $P=.293)$. The adjusted HR for long-term mortality in women was 0.82 (95\% CI, 0.71-0.96; $P=.014)$, indicating that female sex has a beneficial effect on long-term survival after CABG. This observation in our database is clearly shown in Figure 2, in which risk-adjusted Kaplan-Meier curves for men and women are presented. To evaluate the effect of new evolving techniques on sex-related long-term survival, we divided our database in 2 periods of time: 1992 through 1997 and 1998 through 2002, where most innovative techniques were adopted. In men we found that male sex in 1992 through 1997 had no effect on long-term survival when compared with male sex in 1998 through 2002 (adjusted HR, 1.01; 95\% CI, 0.83-1.25; $P=.894$; adjusted for all independent predictors for long-term mortality in the male group, Table 3). Similarly, in women we found that female sex in 1992 through 1997 had no effect on long-term survival when compared with female sex in 1998 through 2002 (adjusted HR, 0.93; 95\% CI, 0.68-1.26; $P=.621$; adjusted for all independent predictors for long-term mortality in the female group, Table 3).

\section{Discussion}

It has been well documented in many studies that women presenting for CABG have a vastly different preoperative risk profile as opposed to that of their male counterparts. Women are consistently older, have more comorbidities, have smaller body surface areas, and present for surgical intervention more commonly on an urgent or emergency basis compared with men. ${ }^{1,3,6,10,11}$ Men reportedly have less preserved left ventricular ejection fraction, present more frequently for $\mathrm{CABG}$ reoperation, have higher rates of 3 -vessel disease, and receive more arterial grafts compared with women. ${ }^{3,6,11,28}$ These differences were confirmed in our database (Table 1). After adjustment for preoperative, intraoperative, and postoperative variables, female sex was not an independent predictor for 30-day mortality (OR, $0.85 ; 95 \% \mathrm{CI}, 0.55-1.31 ; P=.458)$, and this is well in accordance with other studies. ${ }^{10-16}$ It is important to high- light the fact that 4 major postoperative complications (intraoperative stroke, myocardial infarction, gastrointestinal complications, and respiratory failure) were strong independent predictors of 30-day mortality in patients undergoing CABG.

In the current era with improved surgical techniques, there is evidence that no difference exists in long-term survival between women and men undergoing CABG after adjustment for baseline differences. ${ }^{1,4,12,13,15,17}$ In our database, before any adjustment was made, there was no statistically significant difference between women and men in long-term survival (Figure 1). We have shown that EuroSCORE is a strong independent predictor for long-term mortality after $\mathrm{CABG}^{29}$; however, women with a higher EuroSCORE $(7.31$ vs $5.90, P<.001)$ showed similar

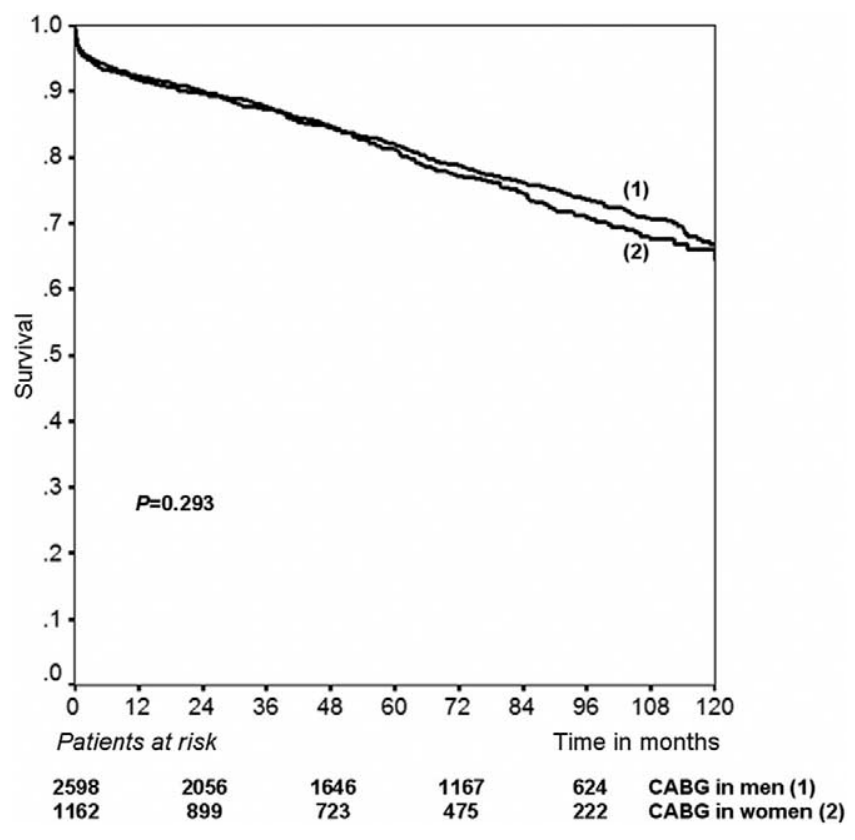

Figure 1. Kaplan-Meier survival plots of men and women undergoing coronary artery bypass grafting (CABG). 
TABLE 3. Independent predictors for long-term mortality (hazard ratios and $95 \%$ confidence intervals) in men and women

\begin{tabular}{|c|c|c|}
\hline Variable & CABG in men & CABG in women \\
\hline $\mathrm{BMI}>29$ & $1.97(1.18-3.29), P=.010$ & - \\
\hline Emergency operation & $1.72(1.29-2.29), P<.001$ & - \\
\hline Previous cardiac operation & $1.44(1.11-1.88), P=.007$ & - \\
\hline PVD & $1.47(1.22-1.78), P<.001$ & - \\
\hline LV hypertrophy & $1.32(1.09-1.59), P=.004$ & - \\
\hline Current CHF & $1.30(1.03-1.64), P=.025$ & - \\
\hline Past CHF & $1.48(1.16-1.88), P=.002$ & - \\
\hline COPD & $1.26(1.02-1.54), P=.028$ & - \\
\hline Preoperative renal failure on dialysis & $2.01(1.18-3.42), P=.010$ & - \\
\hline Preoperative thrombolysis & $0.49(0.32-0.76), P=.001$ & - \\
\hline Intraoperative stroke & $1.91(1.31-2.77), P=.001$ & - \\
\hline Postoperative renal failure & $2.95(1.59-5.45), P=.001$ & - \\
\hline Malignant ventricular arrhythmia & - & $2.37(1.33-4.22), P=.003$ \\
\hline Calcified aorta & - & $1.70(1.19-2.42), P=.003$ \\
\hline Preoperative renal failure & - & $4.10(2.45-6.88), P<.001$ \\
\hline Age & $1.059(1.049-1.070), P<.001$ & $1.063(1.048-1.079), P<.001$ \\
\hline Ejection fraction category $(1:<30 \%, 2: 30 \%-50 \%, 3:>50 \%)$ & $0.79(0.68-0.91), P=.001$ & $0.62(0.51-0.76), P<.001$ \\
\hline Diabetes mellitus & $1.49(1.24-1.80), P<.001$ & $1.37(1.06-1.76), P=.016$ \\
\hline$\geq 2$ Arterial grafts & $0.75(0.63-0.90), P=.002$ & $0.74(0.56-0.98), P=.035$ \\
\hline Postoperative Ml & $2.16(1.01-4.60), P=.046$ & $3.62(1.46-8.96), P=.005$ \\
\hline Deep sternal wound infection & $2.16(1.18-3.97), P=.001$ & $3.62(1.71-7.67), P=.001$ \\
\hline Sepsis, endocarditis, or both & $2.44(1.44-4.14), P=.001$ & $2.72(1.20-6.15), P=.017$ \\
\hline Gastrointestinal complications & $1.73(1.06-2.82), P=.029$ & $3.59(1.64-7.88), P=.001$ \\
\hline Respiratory failure & $2.09(1.46-2.97), P<.001$ & $2.51(1.63-3.86), P<.001$ \\
\hline
\end{tabular}

$>C A B G$, Coronary artery bypass grafting; $B M I$, body mass index; $P V D$, peripheral vascular disease; $L V$, left ventricular; $C H F$, congestive heart failure; $C O P D$, chronic obstructive pulmonary disease; $M I$, myocardial infarction.

long-term survival when compared with men. In addition, after adjustment for all preoperative, intraoperative, and postoperative independent predictors of long-term mortality, female sex was an independent predictor of improved long-term survival after CABG (HR, 0.84; 95\% CI, 0.71$0.96 ; P=.014)$. This finding is well in accordance with 3 previous published studies. Jacobs and associates, ${ }^{19}$ in a report from the bypass angioplasty revascularization investigation with 5.4 years of average follow-up, showed for the first time that after adjustment for baseline differences, women had a significantly lower risk for long-term mortality (HR, 0.60; 95\% CI, 0.43-0.84; $P=.003$ ). Abramov and colleagues, ${ }^{10}$ in a series of 4823 patients undergoing CABG (932 women), showed that female sex was protective for long-term survival (HR, 0.40; 95\% CI, 0.16-0.74; $P<$ $.005)$. Similarly, Guru and coworkers, ${ }^{18}$ in a series of 54,425 patients undergoing CABG (12079 women), revealed a time-related mortality for women after CABG. After adjustment for baseline differences, they found that female sex resulted in worse early survival (HR, 1.44; $95 \%$ CI, 1.29-1.61; $P=.02$ ) and equal or better long-term survival (HR, 0.89; 95\% CI, 0.78-1.00; $P=.06$ ) when compared with male sex.

Few studies in the literature have focused on the determination of independent predictors for long-term mortality in the subgroups of female and male patients. Herlitz and colleagues ${ }^{4}$ reported that congestive heart failure and diabetes mellitus were identified as independent predictors for long-term mortality in both women and men, whereas a history of previous myocardial infarction was an independent predictor only in women, and age, renal dysfunction, cerebrovascular disease, intermittent claudication, valvular disease, current smoking, and left ventricular ejection fraction were independent predictors only in men. Mickleborough and coworkers ${ }^{17}$ reported that ejection fraction, congestive heart failure, and peripheral vascular disease were common independent predictors, whereas recent myocardial infarction and preoperative stroke were independent predictors only in women, and age, class IV symptoms, small body surface area, and lack of left internal thoracic artery were independent predictors only in men. In these studies, however, the investigators excluded postoperative variables, arguing that these are complications and hence might not be true independent predictors for long-term mortality after CABG. Contrarily, in the present study we contend that identifying postoperative complications is important because we have already shown that major postoperative complications affect long-term survival after $\mathrm{CABG},{ }^{21,22,30,31}$ and therefore we report a multivariable 


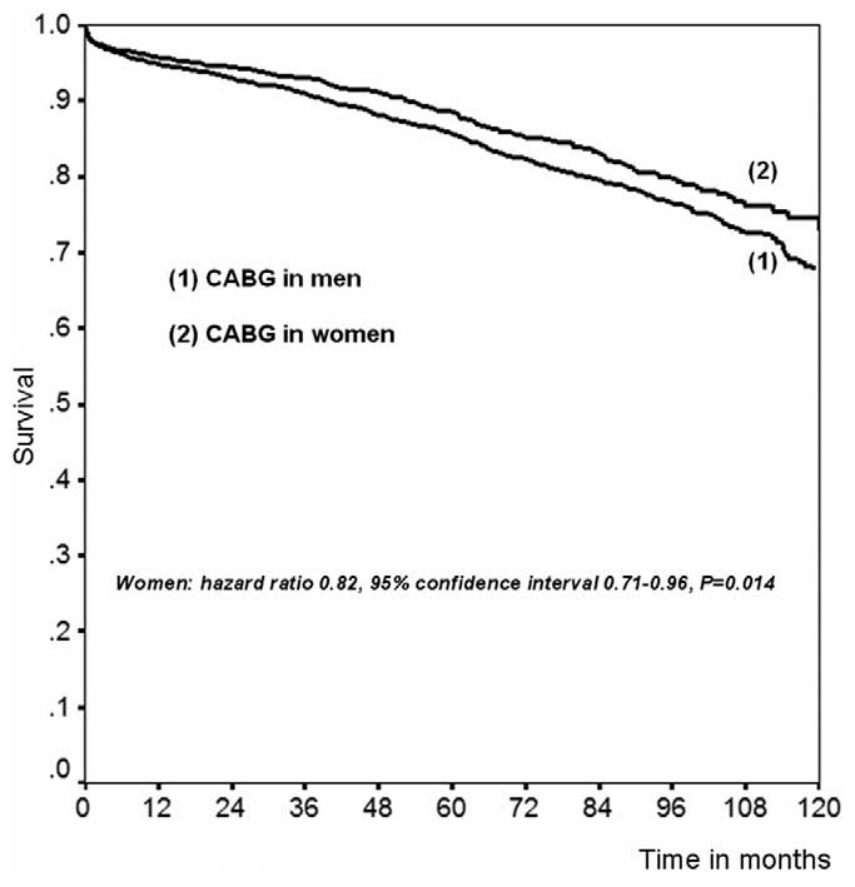

Figure 2. Risk-adjusted Kaplan-Meier survival plots of men and women undergoing coronary artery bypass grafting (CABG) adjusted for all independent preoperative, intraoperative, and postoperative predictors for long-term mortality lage, race, emergency operation, ejection fraction, previous cardiac operation, peripheral vascular disease, $\geq 1$ previous myocardial infarctions, intravenous nitroglycerin, congestive heart failure, malignant ventricular arrhythmia, chronic obstructive pulmonary disease, diabetes mellitus, preoperative renal failure, preoperative renal failure on dialysis, thrombolysis, off-pump coronary artery bypass, $\geq 2$ arterial grafts, intraoperative stroke, postoperative myocardial infarction, deep sternal wound infection, sepsis and/or endocarditis, gastrointestinal complications, and respiratory failure).

analysis, including postoperative variables, which renders our study unique.

Common independent predictors of long-term mortality after CABG include age, ejection fraction, diabetes mellitus, 2 or more arterial grafts, and 5 postoperative complications, such as postoperative myocardial infarction, deep sternal wound infection, sepsis and/or endocarditis, gastrointestinal complications, and respiratory failure (Table 3). The weight of age is different between women and men, and this might be simply a result of the fact that women survive longer in the general population. As the ejection fraction increases (from $<30 \%$ to $>50 \%$ ), the beneficial effect on long-term survival is more apparent in women. Diabetes mellitus was found to have more detrimental effect on long-term survival in male patients. The use of 2 or more arterial grafts is almost equally beneficial for both sexes, indicating that the use of arterial grafts should not be denied in female patients. It is noteworthy that all 5 common postoperative complications have a more detrimental effect on long-term survival in female patients. Therefore a possible strategy leading to prevention of such complications in women undergoing $\mathrm{CABG}$ might further improve their long-term survival outcome.

We were also able to determine unique independent predictors for long-term mortality in women and men undergoing CABG. Peripheral vascular disease was an independent predictor only in men, whereas calcified aorta, another manifestation of vascular disease, was an independent predictor only in women. This difference between the 2 sexes might be related to body size, and thus in women with significantly smaller body surface area, the presence of calcified aorta might constitute a significant predictor, despite the fact that body surface area per se in our study was not an independent predictor for long-term mortality. Preoperative renal failure on dialysis was an independent predictor only in men, whereas preoperative renal failure (serum creatinine level, $>220 \mu \mathrm{mol} / \mathrm{L}$ ) was an independent predictor only in women. We hypothesized that this difference might be related to indecisiveness regarding preoperative dialysis in small-sized women. Malignant ventricular arrhythmia was an independent predictor only in women, and body mass index of greater than 29, emergency operation, previous cardiac operation, left ventricular hypertrophy, congestive heart failure, chronic obstructive pulmonary disease, preoperative thrombolysis, intraoperative stroke, and postoperative renal failure were independent predictors only in men, indicating significant differences in the assessment of independent predictors for long-term mortality after CABG between the sexes. Regarding malignant ventricular arrhythmia in women, our hypothesis is based on the different treatment of women with congestive heart failure ${ }^{32}$ and possibly less defibrillator use. It is known that women form a group that is treated differently, and this was also confirmed in the present study, in which women received fewer arterial grafts and anastomoses. However, these are only hypotheses and warrant further study.

There are several limitations in this study. This was a retrospective investigation and therefore lacks the sensitive methodology for assessment of some postoperative events. Nevertheless, the data on preoperative and postoperative risk factors were collected with the highly standardized methods for the New York State-audited database. This study referred to a single-center regional database, and thus the results require further evaluation across diverse institutions and countries. Although the cause of death in these patients was not documented and was not necessarily cardiac related, the majority of late deaths occurring in men and women after CABG are cardiac related. ${ }^{4,12}$ Survival in relation to graft patency was unknown in the present study. 
Another limitation of this observational study was that there might have been unmeasured confounding variables that affected the findings of sex-independent predictors, as well as long-term mortality survival outcome. In general, there were not significant differences in anesthetic technique, surgical technique, and use of early postoperative aspirin and continuation of chronic medications at discharge between women and men. However, we do not have these data in detail, and we cannot include these variables in our statistical analyses.

In conclusion, dissimilarities in profiles between female and male patients might contribute to the debate about sex differences in outcome after CABG. Although the longterm benefits of CABG surgery both in women and men are clear, further study is needed to explore ways to reduce further early and long-term mortality in the 2 sexes. This procedure starts from the assessment of the independent predictors to determine these factors, which are susceptible to modification. We showed in the present study that the independent predictors for long-term mortality are different between women and men, and therefore clinical decision making, proper attention to specific risk factors, and follow-up should not be influenced by stereotypes derived by the entire $\mathrm{CABG}$ population but by specific findings affecting each sex. The need for an independent, multicenter, prospectively designed study is warranted from the present report to address these important issues.

\section{References}

1. Brandrup-Wognsen G, Berggren H, Hartford M, Hjalmarson A, Karlsson T, Herlitz J. Female sex is associated with increased mortality and morbidity early, but not late, after coronary artery bypass grafting. Eur Heart J. 1996;17:1426-31.

2. Davis KB, Chaitman B, Ryan T, Bittner V, Kennedy JW. Comparison of 15-year survival for men and women after initial medical or surgical treatment for coronary artery disease: a CASS registry study. Coronary Artery Surgery Study. J Am Coll Cardiol. 1995;25:1000-9.

3. Edwards FH, Carey JS, Grover FL, Bero JW, Hartz RS. Impact of gender on coronary bypass operative mortality. Ann Thorac Surg. 1998;66:125-31.

4. Herlitz J, Brandrup-Wognsen G, Karlson BW, Sjoland H, Karlsson T, Caidahl K, et al. Mortality, risk indicators of death, mode of death and symptoms of angina pectoris during 5 years after coronary artery bypass grafting in men and women. J Intern Med. 2000;247:500-6.

5. Hogue CW Jr, Sundt T III, Barzilai B, Schecthman KB, Davila-Roman VG. Cardiac and neurologic complications identify risks for mortality for both men and women undergoing coronary artery bypass graft surgery. Anesthesiology. 2001;95:1074-8.

6. Vaccarino V, Abramson JL, Veledar E, Weintraub WS. Sex differences in hospital mortality after coronary artery bypass surgery: evidence for a higher mortality in younger women. Circulation. 2002; 105:1176-81.

7. Ferguson TB Jr, Hammill BG, Peterson ED, DeLong ER, Grover FL. A decade of change-risk profiles and outcomes for isolated coronary artery bypass grafting procedures, 1990-1999: a report from the STS National Database Committee and the Duke Clinical Research Institute. Society of Thoracic Surgeons. Ann Thorac Surg. 2002;73:480-9.

8. Nashef SA, Roques F, Michel P, Gauducheau E, Lemeshow S, Salamon R. European system for cardiac operative risk evaluation (EuroSCORE). Eur J Cardiothorac Surg. 1999;16:9-13.
9. Koch CG, Khandwala F, Nussmeier N, Blackstone EH. Gender profiling in coronary artery bypass grafting. $J$ Thorac Cardiovasc Surg. 2003;126:2044-51.

10. Abramov D, Tamariz MG, Sever JY, Christakis GT, Bhatnagar G, Heenan AL, et al. The influence of gender on the outcome of coronary artery bypass surgery. Ann Thorac Surg. 2000;70:800-5.

11. Aldea GS, Gaudiani JM, Shapira OM, Jacobs AK, Weinberg J, Cupples AL, et al. Effect of gender on postoperative outcomes and hospital stays after coronary artery bypass grafting. Ann Thorac Surg. 1999;67:1097-103.

12. Hammar N, Sandberg E, Larsen FF, Ivert T. Comparison of early and late mortality in men and women after isolated coronary artery bypass graft surgery in Stockholm, Sweden, 1980 to 1989. J Am Coll Cardiol. 1997;29:659-64.

13. Koch CG, Weng YS, Zhou SX, Savino JS, Mathew JP, Hsu PH, et al. Prevalence of risk factors, and not gender per se, determines short- and long-term survival after coronary artery bypass surgery. $J$ Cardiothorac Vasc Anesth. 2003;17:585-93.

14. Mickleborough LL, Takagi Y, Maruyama H, Sun Z, Mohamed S. Is sex a factor in determining operative risk for aortocoronary bypass graft surgery? Circulation. 1995;92(suppl II):II80-4.

15. Risum O, Abdelnoor M, Nitter-Hauge S, Levorstad K, Svennevig JL. Coronary artery bypass surgery in women and in men; early and long-term results. A study of the Norwegian population adjusted by age and sex. Eur J Cardiothorac Surg. 1997;11:539-46.

16. Woods SE, Noble G, Smith JM, Hasselfeld K. The influence of gender in patients undergoing coronary artery bypass graft surgery: an eightyear prospective hospitalized cohort study. J Am Coll Surg. 2003;196: 428-34.

17. Mickleborough LL, Carson S, Ivanov J. Gender differences in quality of distal vessels: effect on results of coronary artery bypass grafting. J Thorac Cardiovasc Surg. 2003;126:950-8.

18. Guru V, Fremes SE, Tu JV. Time-related mortality for women after coronary artery bypass graft surgery: a population-based study. $J$ Thorac Cardiovasc Surg. 2004;127:1158-65.

19. Jacobs AK, Kelsey SF, Brooks MM, Faxon DP, Chaitman BR, Bittner $\mathrm{V}$, et al. Better outcome for women compared with men undergoing coronary revascularization: a report from the bypass angioplasty revascularization investigation (BARI). Circulation. 1998;98:1279-85.

20. DeRose JJ Jr, Toumpoulis IK, Balaram SK, Ioannidis JP, Belsley S, Ashton RC Jr, et al. Preoperative prediction of long-term survival after coronary artery bypass grafting in patients with low left ventricular ejection fraction. J Thorac Cardiovasc Surg. 2005;129:314-21.

21. Toumpoulis IK, Anagnostopoulos CE, Toumpoulis SK, De RJ Jr, Swistel DG. Risk factors for sepsis and endocarditis and long-term survival following coronary artery bypass grafting. World J Surg. 2005;29:621-8.

22. Toumpoulis IK, Anagnostopoulos CE, Derose JJ Jr, Swistel DG. The impact of deep sternal wound infection on long-term survival after coronary artery bypass grafting. Chest. 2005;127:464-71.

23. Toumpoulis IK, Anagnostopoulos CE. Does EuroSCORE predict length of stay and specific postoperative complications after heart valve surgery? J Heart Valve Dis. 2005;14:243-50.

24. Williams BC, Demitrack LB, Fries BE. The accuracy of the National Death Index when personal identifiers other than Social Security number are used. Am J Public Health. 1992;82:1145-7.

25. Kaplan EL, Meier P. Nonparametric estimation from incomplete observations. J Am Stat Assoc. 1958;53:547-81.

26. Hosmer DW, Taber S, Lemeshow S. The importance of assessing the fit of logistic regression models: a case study. Am J Public Health. 1991;81:1630-5.

27. Cox DR. Regression models and life-tables. J R Stat Soc. 1972;34: 187-220.

28. O'Rourke DJ, Malenka DJ, Olmstead EM, Quinton HB, Sanders JH Jr, Lahey SJ, et al. Improved in-hospital mortality in women undergoing coronary artery bypass grafting. Northern New England Cardiovascular Disease Study Group. Ann Thorac Surg. 2001;71:507-11.

29. Toumpoulis IK, Anagnostopoulos CE, DeRose JJ, Swistel DG. European system for cardiac operative risk evaluation predicts long-term survival in patients with coronary artery bypass grafting. Eur J Cardiothorac Surg. 2004;25:51-8. 
30. Toumpoulis IK, Anagnostopoulos CE, De RJJ, Swistel DG. Effect of gastrointestinal complications on long-term survival after coronary artery bypass grafting. Eur Heart J Suppl. 2004;25:620.

31. Toumpoulis IK, Anagnostopoulos CE, Ashton RC, Connery CP, Derose JJ, Swistel DG. Risk factors for respiratory failure and long-term survival following coronary artery bypass grafting. Chest Suppl. 2004; 126:855S-6S.

32. Jessup M, Pina IL. Is it important to examine gender differences in the epidemiology and outcome of severe heart failure? J Thorac Cardiovasc Surg. 2004;127:1247-52.

\section{Discussion}

Dr Patricia Thistlethwaite (San Diego, Calif). Thank you, Dr Toumpoulis, for a clear and interesting presentation on the predictors of long-term outcome after bypass surgery in men and women. Your study of a single institution's 10-year experience with gender differences in coronary artery bypass grafting provides valuable information and perspective on a field where practice patterns are rapidly changing. Although most of us would like to know how to improve outcomes in women undergoing cardiac surgery, the literature for risk factors unique to women has been contradictory and difficult to interpret. Certainly we would all like to know if there are specific preoperative risk factors, postoperative complications, or a combination of factors that would be absolute contraindications to surgery in either men or women.

I would like to ask 3 questions. First, in your study at a mean follow-up of 5 years, $20 \%$ of all patients who underwent bypass grafting were dead. If the end point of your study is long-term mortality, the key question is, were these deaths cardiac related or not? With regard to that question, I would say that we know that the average life expectancy in the United States for a man 60 years of age is 74.8 years from the Centers for Disease Control and from the 2000 US census and for a woman is 80.1 years. Given that the average age of the patients in your study was in the mid-60s, I pose the question, are you just showing that women live longer than men in general?

Dr Toumpoulis. Actually we don't have in our data base the information regarding the cause of death. This is a limitation, and we have described this in the limitation section of our study. However, given previous published studies, the literature suggests that the majority of deaths after coronary bypass are cardiac related and we can assume probably that these deaths are equally distributed in the subgroup of women and men.

Regarding the knowledge that women live longer, I also think that this factor may play an important role in determining other factors affecting the long-term outcome.

Dr Thistlethwaite. Do practice patterns that are affecting all of us who do coronary bypass surgery, such as multivessel stenting, repeated percutaneous intervention, the widespread use of offpump techniques, or total arterial revascularization, have any influence on gender outcome? I noted in the manuscript that you provided that very few patients underwent off-pump coronary artery bypass and that men had a much higher frequency of arterial grafting than women.
Dr Toumpoulis. Our group is the leading group in New York in arterial revascularization since the era of Dr Green, and we were late taking up off-pump coronary bypass surgery. However, in our study published the previous year in Heart Surgery Forum we have demonstrated that there were no midterm differences between matched groups using off-pump or conventional CABG. Regarding the use of coronary interventions and the percutaneous transluminal coronary angioplasty used, we don't have this information in our data base. This is another limitation of our study.

Dr Thistlethwaite. Finally, why do you think that ventricular arrhythmia, calcified aorta, and preoperative renal failure are risk factors for long-term mortality in women and not in men? It is not intuitively obvious why there is a gender difference for these risk variables.

Dr Toumpoulis. The reason for these differences cannot be deduced from our study. Calcified aorta may be size related, whereas in the subgroup of men, peripheral vascular disease, another manifestation of peripheral vascular disease, is also responsible for long-term outcome. Renal failure may be related to size regarding postoperative dialysis in small women, Malignant ventricular arrhythmia may develop because women are generally undertreated and fewer defibrillators are used. These are only hypotheses, however. We cannot prove them.

Dr Thistlethwaite. It will certainly be interesting to observe your cohort of patients for a longer period of time to see if your observations hold up at 10 and 20 years after surgery.

Dr Toumpoulis. Thank you very much.

Dr Scott Rankin (Nashville, Tenn). I congratulate your entire group on the excellent studies coming from this data base now. It's a transforming experience to see the good data you are producing.

I have a question about the mechanism of neutralization of outcome differences in female gender. In the late 1980s, David Prior and I wrote a paper that was in Circulation on trends in outcomes in coronary bypass surgery. One of the things we found in the analysis (and I don't think we really published it in the paper) was that female gender in the Duke data base was a risk factor for mortality before 1980 in the Duke databank. This finding appeared to be related to smaller vessels - the women with smaller coronary arteries had a higher mortality. After 1980, however, the effect of female gender seemed to be neutralized. We hypothesized that the increasing use of the internal thoracic artery grafts, with better associated patencies, neutralized the effect of female gender on outcome in women with smaller vessels. Now, you have a certain percentage of patients in this study that did not have internal thoracic grafts. Could you review your findings to see whether you could confirm that hypothesis or not in your data set?

Dr Toumpoulis. It is interesting to test your hypothesis, and I think that our data confirm your conclusion because the use of 2 or more arterial grafts equally improves long-term mortality in men and women. If the difference is based on this difference, we can prove this in our data base. However, we have not done such an analysis in this particular work. 